\title{
Documentos sobre los judíos de Plasencia en el Archivo Catedralicio (1411-1492)
}

Marciano de Hervás

En el Archivo de la Catedral de Plasencia hemos encontrado una gavilla de documentos relacionados con la vida de los judíos en la ciudad del Jerte entre los años de 1379 y 1492, buena parte de ellos reseñados parcialmente en los trabajos publicados por diversos historiadores ${ }^{1}$, aunque en muy contadas ocasiones citan sus fuentes de documentación 2. Predominan en las escrituras los contratos de alquileres de casas y fincas de explo-

1 J. Correa y Roldán, Annales de la Santa Yglesia Catedral de Plasencia desde su fundacion (ca. 1570) (Archivo Histórico Provincial de Cáceres IF AHPC], Legado Paredes, leg. 109, núm. 4); Fr. A. FERnÁndez, Historia y anales de la ciudad y obispado de Plasencia (Madrid 1627); A. MORALES, Privilegios, bulas, donaciones, confirmaciones y otras escrituras que se hallan originales en el Archivo y Tumbo de la Santa Iglesia Catedral de Plasencia 7 (1753) (Archivo de la Real Academia de la Historia, Ms. 9/5427); J. M. ${ }^{2}$ BARRIO Y RUFo, Historia de la Muy Noble y Muy Leal ciudad de Plasencia (Biblioteca Pública de Cáceres [= BPC], Ms. 1); A. MATías GiL, Las siete centurias de la ciudad de Alfonso VIII (Plasencia 1877, $2^{\mathrm{a}}$ ed. 1984); N. DíAZ Y PÉREZ, Extremadura (Barcelona 1887); V. PAREDEs GUILlÉN, Los Zúñigas, señores de Plasencia (Cáceres 1903), y "Los Zúñigas, señores de Plasencia», Revista de Extremadura 6 (1904) págs. 387-399: págs. 393-397, y 9 (1907) págs. 493-501: págs. 498-501, y 556-566: 556-558 y 565; E. ESCOBAR PRIETO, «Los judíos de Extremadura", El Monasterio de Guadalupe I (1 ag. 1916) págs. 6064, y (15 ag. 1916) págs. 74-76; J. BENAVIDES CHECA, Prelados placentinos (Plasencia $1907,2^{\mathrm{a}}$ ed. 1999 ) págs. 77, 80-84, 88-89 y 184.

2 Noticias parciales en D. SÁNCHEZ LORO, El parecer de un deán (Cáceres 1959-1961) e Historias placentinas inéditas vols. A-C (Cáceres 1982-1985); M. LÓPEZ SÁNCHEZ-MORA, La sillería del coro de la Catedral de Plasencia ¿Tallistas judios? (Plasencia 1970), y Plasencia siglos XVI y XVII (Plasencia 1977); E. C. de Santos Canalejo, El siglo XV en Plasencia (Cáceres 1981); así como en la más documentada obra de J. M. LóPEz MARTín, Paisaje urbano de Plasencia en los siglos XV y XVI (Badajoz 1993). 
tación agrícola, y de ventas de los bienes de los judíos exiliados en 1492. Sin embargo hemos centrado nuestra atención en el espacio urbano que ocupa la aljama hebrea en el siglo XV, sus bienes comunales, actividades profesionales y el desplazamiento de la judería a otra barriada en 1477-1480. De este manojo de escrituras hemos seleccionado una docena de documentos recogidos en el apéndice documental que nos permiten mostrar aspectos específicos del judaísmo placentino.

Es menester tener en cuenta dos consideraciones históricas transcendentales sobre la situación política y religiosa que experimenta la ciudad en el transcurso del siglo XV. En el ámbito político el soberano Juan II (1406-1454) es propietario de Plasencia y su tierra (42 aldeas repartidas en tres sexmos) hasta que el 30 de diciembre de 1442 la otorga al conde Pedro de Zúñiga en trueque por la de Trujillo. Su primogénito Álvaro de Zúñiga hereda el señorío de Plasencia el 15 de agosto de 1453, cuyo gobierno hemos dividido para mejor comprensión del trabajo en dos etapas: la primera abarca hasta 1477 , fecha de la expropiación de los bienes comunales y privados hebreos de la calle Coria; y la segunda concluye en 1488 , año en que Plasencia y sus aldeas retornan a la corona ${ }^{3}$.

En el aspecto religioso, el obispo converso Gonzalo de Santa María, hijo del que fuera rabino de Burgos, Šelomó ha-Leví, es obispo electo de Plasencia en julio de $1423{ }^{4}$, pero no toma posesión del cargo hasta después de diciembre de $1424{ }^{5}$. Su primera actuación oficial es de 9 de enero de $1427 .{ }^{6}$, y la última de 27 de setiembre de $14488^{7}$. Es muy posible que con el obispo Gonzalo de Santa María se asentasen en la ciudad del Jerte familiares conversos ${ }^{8}$. A este le sucede el obispo Juan de

3 AHN, Sección Nobleza, Osuna, leg. 257, núm. 45, y legs. 303/2.

${ }^{4}$ C. EuBel, Hierarchia Catholica Medii Aevi sive summorum Pontificum (Munich 1899) vol. I págs. 168 y 407; citado por F. GoNZÁleZ CUESTA, «Sobre el episcopologio de Plasencia», Hispania Sacra 47 (1995) págs. 347-376: pág. 369.

${ }^{5}$ ACP [= Archivo de la Catedral de Plasencia], ACC (= Actas del Cabildo Catedralicio), Libro núm. 1, fols. 43-45.

${ }^{6}$ ACP, ACC, Libro núm. 1, fol. 56; citado por CORREA y ROLdán Annales fols. 34-36

7 ACP, ACC, leg. 269, núm. 25. En esa fecha se encontraba en Burgos.

8 Posibles familiares del obispo converso pueden ser García Jiménez, su criado; cfr. ACP, ACC, Libro núm. 1, fols. 129v y 130v; y Alfonso García de Santa María, arcediano de Trujillo (1435) y tesorero de la catedral (1445-1450), que vive cerca 
Carvajal (1446-1470), de la familia Carvajal de Plasencia, ambos caracterizados por su absentismo en la sede episcopal ${ }^{9}$.

\section{El apartamiento de 1412 y los edificios Comunales HEBREOS}

De la judería de Plasencia sabemos que en el ecuador del siglo XIV habita en la calle Zapatería un «judio que hace las cintas» ${ }^{10}$. En 1386 Alazar arrienda al cabildo una vivienda en la Plaza que está junto al hospital y la casa del arcediano de Plasencia ${ }^{11}$. En 1391 Menahén reside en una casa de la calle Trujillo, propiedad de Miguel Sánchez Yanguas, «cerca de las casas de Diego Gómez de Almaraz e de casas de Iohan Clemeynte racionero» ${ }^{12}$. Un tal Yudá vive «encima del meson de la Talauerana» ${ }^{13}$ en 1394. Y en 1403 don Yaco Albelia reside en la calle Sol esquina a la Plaza ${ }^{14}$. De modo que a principios del siglo XV un sector de la comunidad hebrea habita en la Plaza y y en la calle Trujillo.

Consideramos que los acontecimientos que tienen lugar en la Hispania cristiana contra las juderías de Castilla entre los años de 1391 y 1412 afectan a la aljama de Plasencia. Así, en la segunda década del siglo XV la comunidad hebrea tiene «çierta juderia apartada en la dicha çibdad e çerca della vna sinoga la mejor e mas antigua que auia en toda Estremadura» ${ }^{15}$ de la que no tenemos más información. En el inventario de bienes del cabildo catedralicio de $1403{ }^{16}$ no hay noticias de arrendamientos de casas a los judíos, que se inician en $1434{ }^{17}$,

de la calle Trujillo; cfr. ACP, ACC, Libro núm. 1, fols. 83 y 142v; y Libro núm. 3, fol. 195v; así lo sugiere SÁNCHEZ LoRo Historias B pág. 400.

9 J. L. Martín Martín, "Los obispos de Extremadura en la Edad Media», Revista de Estudios Extremeños 47 (1991) págs. 67-98: pág. 95.

10 BPC, Legado Paredes, Ms. 1, «3० Apuntamiento con indice», fol. 565.

1 AHPC, Legado Paredes, leg. 13, núm. 11, fol. 12.

12 Benavides Checa Prelados pág. 184; recogido por SÁnCHEZ Loro Historias C pág. 254.

${ }_{13}$ ACP, leg. 12, núm. 24, fol. 3.

${ }_{14}$ ACP, ACC, Libro núm. 1, fol. 17v; Biblioteca del Seminario Mayor Diocesano de Plasencia (= BSMDP), Legado Benavides Checa, «Notas del cabildo de Plasencia».

15 AGS, Registro General del Sello (= RGS) (11 mayo 1491) fol. 86.

${ }_{16}$ AHPC, Legado Paredes, leg. 13, núm, 11, fols. 33, 64 y 72.

17 ACP, ACC, Libro núm. 1, fol. 77v. 
año en que estos conciertan con el cabildo catedralicio el arrendamiento de casas en calles específicas de la población. En 1439 la aljama hebrea atraviesa un período de crisis que afecta a su demografía y economía ${ }^{18}$ :

Otrosy la aljama de los judios de Plasençia tiene de cabeça de pecho en cada año 10.200 [mrs.] de moneda vieja, e por quanto los dichos judios eran pocos e pobres fisoles merçed el dicho señor rey que non pagasen dello este dicho año de 1439 año mas de 3.500 desta moneda blanca, e despues de conplido este dicho año han de pagar los dichos judios los dichos dies mill mrs. de moneda vieja cada año.

Así pues, el noble Pedro de Zúñiga recibe en 1442 una aljama empobrecida y diezmada. En los días de su gobierno localizamos la sinagoga en la calle Coria, en la zona de la Mota, donde hoy se levanta el antiguo convento de San Vicente Ferrer, futuro Parador Nacional, próxima a un edificio conocido como la «caballeriza» ${ }^{19}$. La casa de la caballería grande es propiedad de Pedro Suárez, sita en la calle Rúa, que linda con la calle Arenillas y por detrás con la calle Esparrillas ${ }^{20}$. ¿Se refiere a la misma caballeriza? ${ }^{21}$.

Al pie de la puerta de Coria nace la cerca de la Mota, y continúa adelante 22 :

çerca do se dize que esta el pozo de las casas caydas que fueron de rebi Abrahen, e viene e vaya a dar al esquina del palaçio mayor mio, questa fuera del cuerpo del dicho mi palaçio, e

18 AGS, Escribanía Mayor de Rentas, leg. 1/4, fol. 174; en fol. 173v: «la cabeça de pecho de los judios de Plasencia 800»; publicado por F. BAER, Die Juden im christlichen Spanien. Urkunden und Regesten, II: Kastilien/Inquisitionsakten (England 1970) págs. 307-308; y M. A. LADERO QUESADA, "Las juderías de Castilla según algunos "servicios" fiscales del siglo XV", Sefarad 31 (1971) págs. 249-264: pág. 254.

19 AHN, Sección Nobleza, Osuna, leg. 215/3, núm. 10/2, citado por M. A. LADERO QUESADA, «Rentas condales en Plasencia (1454-1488)», en Homenaje a don José María Lacarra de Miguel (Zaragoza 1977) vol. IV págs. 235-265: pág. 256.

${ }^{20}$ ACP, leg. 2, núm. 34, fols. 36v-37.

${ }_{21}$ No compartimos el criterio de MATías Gil Centurias pág. 141, quien sugiere que la casa de rabí Abrahán podría estar en la calle Arenillas esquina con la calle Rúa.

22 AGS, RGS (20 jun. 1511); citado por Morales Privilegios fol. 310; Paredes Guillén Zúñigas pág. 125; Benavides CheCA Prelados págs. 159161; SÁNCHEZ LoRo Historias C págs. 236-237. 
que se siguia por la pared del dicho palaçio nuevo a dar en la çerca vieja de la dicha çibdad de Plasençia.

También en la calle Coria está la cofradía de los judíos, enfrente del atrio y cementerio de la iglesia parroquial de San Nicolás. En 1461 linda el inmueble judío con la casa de García de Carvajal, hijo de Isabel de Carvajal, «e a las espaldas de las dichas casas e casar con la pared de la Mota, enfrente de la casa de la cosina del dicho señor conde» ${ }^{23}$. Posiblemente esta cofradía tiene como misión subvenir las necesidades de los pobres u organizar los enterramientos fúnebres hebreos.

En la Plaza Mayor hay dos carnicerías cristianas situadas debajo de los soportales que se extienden desde la entrada de la calle Sol a la Plaza de San Esteban: una en uel rencon de la Plaça e las otras que estan a linde de Pedro de Algul» ${ }^{24}$. Quizá la carnicería judía podría encontrarse en la Plaza. Allí mismo vive Abrahán Chicala en 1434, en la casa de la panadería ${ }^{25}$.

Otra de las propiedades comunales de los judíos son los osarios viejo y nuevo que se encuentran a espaldas de la judería en el sitio del Berrocal, próximo a la puerta Berrozana ${ }^{26}$. El cementerio judío abarca una parcela del Berrocal pero no es tan extenso como apunta fr. A. Fernández ${ }^{27}$. De hecho, el cementerio hebreo limita «con los exidos e tierras concejiles desta cibdad» ${ }^{28} \sin$ llegar al río Jerte ni al puente de San Lázaro.

\section{LA JUdería DE PlasenCIA EN 1442-1477}

El apartamiento hebreo de la calle Coria pudo efectuarse a raíz del ordenamiento de las Cortes de Valladolid de $1412{ }^{29}$,

\footnotetext{
23 ACP, ACC, Libro núm. 3, fol. 162; vid. el Apéndice infra, doc. 4.

24 AMP, «Actas Municipales (1461-1465)» fol. 43v; cfr. López MARTín Paisaje urbano págs. 218-219. E. CARolina DE SAntos CANAlEjo, La Historia medieval de Plasencia y su entorno geo-histórico (Cáceres 1986) pág. 458, sugiere que los establecimientos judíos y cristianos se hallaban en la Plaza.

${ }_{25}$ ACP, ACC, Libro núm. 1, fol. 80; y Benavides CheCA Prelados pág. 80.

26 Véase Apéndice infra, docs. 11/1 a 11/3.

27 Véase la descripción en FERnÁndez Anales fol. 154, y PAREdEs GuilléN Zúñigas pág. 129.

28 Véase Apéndice infra, doc. 11/2.

29 En 1395 el judío Menahén vive en la calle Trujillo; cfr. BENAvides CHECA Prelados pág. 184; y en 1403 don Yaco Albelia en la calle Sol; cfr. BSMDP, Legado Benavides Checa, «Cabildo».
} 
sin embargo en la década de los años 30 pierde su carácter marginal presentándose como un espacio abierto. En los primeros años del gobierno de los Zúñiga, judíos y cristianos comparten la arteria urbana de la calle Coria donde hay solares sin edificar. En 1464 el conde de Plasencia concede a Juan de Pineda un solar en el altozano de la calle Coria, cerca de San Nicolás, y otro solar a Rodrigo de Soria en la misma puerta de Coria para construir una casa; Pedro Carpintero recibe del municipio un solar en la puerta de Coria también para edificar una vivienda ${ }^{30}$.

En la Plazuela de San Nicolás confluyen las calles Coria y Rúa o Zapatería. En 1428 habitan en la Rúa Abrahán Sarco, albardero, y Çid Bueno, zapatero ${ }^{31}$. Entre los años de 1436 y 1442, ciclo de la corona, encontramos en la calle Rúa a Yuçef Chapus Aranón que tiene una casa alquilada al cabildo (1436) traspasada a su hermano Abrahán Aranón (1441) y quizá lue-. go a Mosé Aranón ${ }^{32}$. También hallamos al converso Diego Jiménez de Burgos, sobrino del obispo Gonzalo de Santa María ${ }^{33}$, a Çag Escapa que tiene por vecino a Yuçef Molho (1442) ${ }^{34}$, a rabí Yudá (1442) ${ }^{35}$ y al matrimonio Çid Bueno y doña Reyna que habitan en la casa que está junto a la torre de Fernán Núñez ${ }^{36}$.

Entre los años de 1442 y 1477 hallamos a los inquilinos Abrahán Abenacin (1453) ${ }^{37}$, Salamón Daça (1454) ${ }^{38}$, Yucé Caçes hijo de Mosé Caçes (1455) ${ }^{39}$, Eça Aruso yerno de Ancho, Yuçé Pardo que habita en la primera casa de la calle entrando por la

30 AMP, «Actas Municipales (1461-1465)» fols. 26v, 27 y 32.

31 BSMDP, Legado Benavides Checa, «Provisores de Plasencia» (28 en. 1428).

32 ACP, ACC, Libro núm. 1, fols. 87 y 125-126v; y Libro núm. 3, fol. 137; los datos de nuestras notas $34-40,42-45,47-49$ y 51 infra están recogidos en PAREdes Guillén Zúñigas págs. 61-62 y 128-129, BenAVIdes CheCA Prelados págs. 77, 80-84 y 88-89, y LóPEz MARTín Paisaje urbano págs. 120-121, 132, 189 y 216.

33 Véase Apéndice infra, doc. 3.

34 ACP, ACC, Libro núm. 1, fol. 132v.

35 ACP, ACC, Libro núm. 3, fol. 182.

36 ACP, ACC, Libro núm. 3, fol. 137.

37 BSMDP, Legado Benavides Checa, «Cabildo» (1ºn. 1453). La lectura del apellido podría ser también Abençur.

38 ACP, ACC, Libro núm. 3, fol. 179v.

39 ACP, leg. 5, núms. 41 y 34. 
Plaza a mano izquierda, y Yuçé Daça que reside enfrente de la herrería de Sentó (1455) ${ }^{40}$. Otros moradores son doña Vellida mujer de Yebdá Abenataf vecina de don Hayn Moxudo (1461) ${ }^{41}$, Yuçé Caçes (1464) ${ }^{42}$, Beroha, que vive muy cerca de la casa de la mujer de Gatellos (1468) ${ }^{43}$, Abrahán Abençur (1469) ${ }^{44}$, Hayn Castro (1472) ${ }^{45}$ y Yuçé Castaño (1474) ${ }^{46}$. Saúl Daça y Yudá Fidauque compran una casa a Diego González de Carvajal cuyo edificio linda con la vivienda de la mujer de Salamón Matraco y la de Simuel Aranón (1477), pero en octubre del mismo año Saúl Daça la vende a Yudá Fidauque, que ahora tiene por vecino a Ester, mujer de Salamón Abenhabibe, y a Simuel Aranón ${ }^{47}$.

Por consiguiente, la calle Rúa es una prolongación de la judería de la calle Coria en su trayecto hacia la Plaza ${ }^{48}$, otra de las áreas urbanas elegidas por los judíos. De 1434 a 1442 habitan en la Plaza Abrahán Chicala, en la casa de la panadería (1434) ${ }^{49}$, Yuçé Caçes (1440) ${ }^{50}$, Simuel Aruso y su hermano Yuçé Aruso, ambos hijos de Abrahán Aruso, que tienen por vecino a Adorraheme, musulmán ${ }^{51}$.

En los días de los Zúñiga reside en la Plaza Yaco Çanfán, en una vivienda propiedad de Diego González de Carvajal ${ }^{52}$, don Mayr Cohén en la casa que hace esquina con la calle San Martín (1460) ${ }^{53}$ y don Salamón, su mujer doña Graçia y su hijo Isaque en la casa de la zapatería cuya vivienda linda con el

40 ACP, leg. 14, núm. 25, fol. 10: «Eça Harruso ... Yuçe Pardo»; y fol. 20: «Eças Haruso ... Yuçe Peres».

41 Véase Apéndice infra, doc. 5.

42 ACP, ACC, Libro núm. 3, fol. 166.

${ }^{43}$ ACP, ACC, Libro núm. 3, fol. 167v.

${ }^{44}$ ACP, ACC, Libro núm. 3, fol. 170v.

${ }^{45} \mathrm{ACP}, \mathrm{ACC}$, Libro núm. 3, fol. 175v.

${ }^{46}$ Véase Apéndice infra, doc. 7.

47 Véase Apéndice infra, doc. 10; y leg. 5, núm. 30.

48 «... vnas casas caydas que estan en la Plaça baxo de la çapateria que han por linderos ... de otra parte la calle Real que va a la puerta de Coria" (véase Apéndice infra, doc. 6.).

${ }^{49}$ ACP, ACC, Libro núm. 1, fol. 80.

50 Véase Apéndice infra, doc. 2.

51 ACP, ACC, Libro núm. 1, fol. 142; de donde lo toma López MARTín Paisaje urbano págs. 216 y 221.

52 ACP, leg. 14, núm. 25, fol. 10: «Yaco Çafra», y fol. 20: «Yaco Çanfan».

53 ACP, ACC, Libro núm. 3, fol. 160. 
corral de la mujer del converso Diego Jiménez de Burgos (1471) ${ }^{54}$. También hallamos a Yuçé Escapa, su mujer doña Oriçeti y su hijo Simuel Escapa, vecinos de Isaque Molho (1472) ${ }^{55}$. Hayn Moxudo y su mujer Amira son propietarios de un tercio de la casa que venden a don Mayr Cohén (1488), los otros dos tercios pertenecen a Salamón Caçes y a su tío Jaco Moxudo, que opera de fiador en la venta del inmueble ${ }^{56}$.

En la calle Trujillo el cabildo arrienda una casa a un judío cuyo nombre no citan las escrituras y otras tres viviendas a Yuçé Lerma ${ }^{57}$. Y en la calle del Sol vive un tal Reiço (1457) ${ }^{58}$.

De modo que entre los años de 1442 a 1477 los judíos ocupan numerosas viviendas que arriendan a la clerecía de Plasencia. La parroquial de Santiago alquila a un judío una casa de su propiedad en la calle Rúa y el cabildo catedralicio dieciocho viviendas distribuidas en los lugares de la Plaza (3), Trujillo (3), Rúa (9), San Martín (2) y Sol (1). Por su parte, Diego González de Carvajal y Alfonso Ruiz de Camargo venden una vivienda a los judíos en la calle Rúa y dos propietarios judíos transfieren sus casas de la calle Rúa a otros judíos.

Asimismo los judíos tienen sus edificios comunales en la calle Coria (sinagoga y cofradía) y la Plaza (carnicería) pero sus viviendas están centradas en la calle Rúa y en menor grado en la Plaza y calle Trujillo.

\section{La nueva sinagoga y Judería de la Calle Trujillo (1477-1488)}

El trazado urbano de la judería cambia parcialmente con las reformas que proyectan los condes de Plasencia sobre el sitio de la Mota en el verano de 1477. El 22 de julio doña Leonor Pimentel, sobrina y segunda esposa de Álvaro de Zúñiga, señor de Plasencia, decide construir un monasterio bajo la advocación del dominico Vicente Ferrer para lo cual expropia

\footnotetext{
${ }_{54}$ Véase Apéndice infra, doc. 6.

55 ACP, ACC, Libro núm. 3, fol. 174.

56 Véase Apéndice infra, doc. 10.

${ }^{57}$ ACP, ACC, Libro núm. 3, fols. 78v-79.

${ }_{58} \mathrm{ACP}$, leg. 1, núm. 1, fol. 14; el texto presenta una mancha de tinta que dificulta la lectura del patronímico hebreo.
} 
la sinagoga de los judíos situada en la Mota, muy cerca del pozo de las casas caídas de rabí Abrahán ${ }^{59}$. A juicio de V. Paredes los muros «de la huerta aneja [del convento de San Vicente] se hicieron con escombros de la sinagoga y de la parte del palacio mayor, que derribaron, y algunos materiales nuevos, según se ve hoy en la calle de Arenillas» ${ }^{60}$.

El traslado de la sinagoga a otro inmueble coincide con los días en que tiene lugar la promulgación de la ley de Cortes de Toledo de 1480, que estipula el apartamiento de los judíos en barrios aislados de los cristianos, cuya medida da pie a la comunidad judía para solicitar al corregidor de la ciudad, sometido a la obediencia del conde de Plasencia, «que les diesen sitios e les señalasen juderia ... el qual le señalo en logares despoblados en lo peor separado que era" ${ }^{61}$.

De este modo, la comunidad hebrea de Plasencia construye la nueva sinagoga en la calle Trujillo: «labraron casas muy buenas e fisieron vna sinoga y que estandola fasiendo vyno a la sason a la dicha çibdad por nuestro mandado el visitador que tenia cargo de faser apartar los dichos judios» 62.

Encontramos datos más precisos sobre el emplazamiento, construcción y dependencias del edificio sinagogal en un documento de 1539 63:

el dicho casar e solar que fue donde estava la dicha yglesia de Santa Ysabel que primero fue casa o sinoga de judios ... esta en esta çibdad de Plazençia junto con la calle publica que se llama de Trugillo e confina por la una parte con vna calleja que va a vna plaçeta que dizen de Rodrigo de Carvajal [Plaza

59 Véase nota 22. El convento se encuentra en obras, cuyos resultados expondrán en su día los arqueólogos doña Cristina Sánchez Hernández y don Pedro Matesanz Vera.

60 Paredes Guillén Züñigas pág. 126, y «Zúñigas» 9 (1907) págs. 556-558 y 565 .

61 AGS, $R G S$ (11 mayo 1491) fol. 86

62 AGS, RGS (11 mayo 1491) fol. 86

63 ACP, leg. 269, núm. 17, fol. 7v: «Donazion que la reyna doña Ysabel hizo al cauildo de la sinagoga de los judios que despues fue yglesia de Santa Isabel y los autos que se hiçieron contra los que quemaron la dicha yglesia y la sentençia que sobre ello se dio. Passo ante los señores dean de Plasençia y arzediano de Truxillo"; resumido por PAREDES GUILLÉN Zúñigas págs. 126-127, y LóPEZ SÁNCHEZ-MORA Plasencia págs. 127-131. Hay varias hojas manuscritas sueltas con un resumen en ACP, leg. 86, núm. 9, fol. 139. 
de Ansano], vezino e regidor desta dicha çibdad, e de otra parte con casa de Gonçalo Gonçalez e con casas de Agustin Cabreros, y por la otra parte la plaçuela de Santa Ysabel y por la otra parte casas de Juan Lopes texedor.

Además del recinto destinado para la oración comunitaria, la sinagoga tiene «tres casyllas e que estan junto con ella que dis que eran suyas e de su servidumbre» ${ }^{64}$. Estas tres casillas son sin lugar a duda dependencias anexas al edificio religioso principal destinadas para satisfacer las necesidades de culto y otros servicios de los judíos ${ }^{65}$.

En el auto celebrado en Plasencia en 1539 contra los incendiarios del inmueble de la sinagoga, diversos testigos ofrecen información pormenorizada sobre aspectos concretos del interior del edificio. A juicio de Alonso de Cáceres, la mesa capitular «dio a çenso çierta parte de la dicha synagoga a çiertos señores, que fue la parte adonde se metian las judias a hazer oraçion syendo synoga apartadas de los varones» ${ }^{66}$.

Francisco Heras, antiguo mayordomo de la mesa capitular, declara que los administradores del cabildo «dieron a çenso çierta parte que sale a la hazera de la calle de Trugillo a Gonçalo Gonçalez vezino desta çibdad, que hera anexo a la dicha yglesia de Santa Ysabel» ${ }^{67}$.

Un tercer apunte informa del «contrato de çenso que hiso Gonçalo Gonçales [e] tomo del cauildo a çenso tres casillas junto a Santa Ysabel, da por ellas myll e dozientos mrs» ${ }^{68}$.

Por consiguiente, de los testimonios recabados sabemos que una de las tres salas de la sinagoga es la galería de las mujeres, la cual está orientada hacia el acerado de la calle Trujillo ${ }^{69}$.

64 ACP, leg. 282, núm. 11, fol. 1v (2 feb. 1493).

65 Las sinagogas de los barrios judíos de Trujillo y Plasencia se construyen en 1480 . Sobre la sinagoga de Trujillo cfr. J. L. LACAVE, «Sinagogas y juderías extremeñas», Sefarad 40 (1980) págs. 215-234: págs. 218-221; sobre la de Coria cfr. M. de HERVÁs, «La sinagoga de Coria en la documentación de los Archivos Catedralicio y Municipal», en Actas del I Encuentro Transfronterizo sobre Patrimonio Histórico de la Raya/A Raia (Coria 1999, en prensa).

66 ACP, leg. 269, núm. 17.

67 ACP, leg. 269, núm. 17.

68 AHPC, Legado Paredes, leg. 13, núm. 10, sin foliar.

69 En la sinagoga se construyó «puede aver obra de veynte años $\ 1519$ ó $1520 /$ a esta parte estando en la dicha yglesia haziendo la capilla mayor y otra capilla» (ACP, leg. 269, núm. 17, declaraciones de Juan Correa). Los años se han añadido en fecha posterior encima de la primera línea. 
Las otras dos dependencias tenían distintos usos comunitarios. Asimismo en el centro del edificio arrancan «unos pilares» 70 que sustentan la techumbre.

La expropiación forzosa de los inmuebles hebreos de la calle Coria cambia el marco de la judería de Plasencia iniciándose un movimiento migratorio judío hacia la calle Trujillo. Inmediatamente después de que la corona ratifica el apartamiento de la calle Trujillo y se construye la sinagoga, los judíos arriendan solares a los Carvajal, enemigos encarnizados de los Zúñiga. Así, Ysay de Oropesa alquila a Rodrigo González de Carvajal un solar que tiene a las espaldas de la casa en la calle Trujillo (1482) e Ysay Pachén y Yudá Caçes ocupan los solares linderos en una fecha anterior ${ }^{71}$. Ese mismo año Jaco Loçano alquila otro solar a los Carvajal en la calle Trujillo, limítrofe con el que tiene en renta Abrahán Loçano y con los «solares de Aljesiras» ${ }^{72}$. Pero los codiciados corrales de Algeciras, también propiedad de los Carvajal, son arrendados a Pedro Gutiérrez Quijada, alcaide de la fortaleza (30 ag. 1485), a cuya vera está la casa de Yudá Alegre ${ }^{73}$. Doña Vellida, viuda de Salamón Molho, vende a su yerno Yuçé Aruso «vnas casas que yo he tengo en la juderia de la calle de Trugillo de la dicha çibdad de Plazençia, que alindan de la vna parte con casas de Abrahan Cohen mi yerno e de la otra parte con casas de Yuçe Medellin» ${ }^{74}$ (jun. 1485). Leví Alegre arrienda a los Carvajal «vn solar en los corrales de las Algeziras, el prosimo que es en la calle de Trujillo que alinda de la vna parte con Yuda e Symuel Alegre, sus firmanos» ${ }^{75}$ (set. 1485). En el mayorazgo fundado por Rodrigo González de Carvajal (en. 1485) se incluyen las rentas de «todos los censos de los solares que tienen los judios que salen a la calle de Trugillo e con tres corrales que tienen

\footnotetext{
${ }^{70}$ ACP, leg. 269, núm. 17 (declaraciones de Alonso Almaguer).

71 ACP, leg. 1, núm. 42.

72 ACP, leg. 3, núm. 11.

73 AMP, sin catalogar, fol. 1: «Pertenenzias de 1.000 mrs. de renta y zenso perpetuo en cada vn año sobre vnas casas y corrales en la calle de Truxillo de esta ciudad a favor del Hospital de la Merçed, que oy paga don Ansano de Carbajal por tener dicha tasa incorporada en el prinçipal del Mayorazgo que corresponde a la calle de Truxillo. Oy paga este zenso don Francisco de Paula Vargas y Carvajal».

74 Véase Apéndice infra, doc. 9.

${ }^{75}$ ACP, leg. 5, núm. 42.
} 
ansi mismo arrendados los dichos judios de los que tienen los solares mas baxos» ${ }^{76}$. Quizá en la planta baja de estas casas instalan los judíos sus talleres artesanales o comercios. Un tal Isaac que vive en la «calle de Trugillo a la entrada della, es la segunda casa a mano izquierda", traspasa el censo de la casa, propiedad del cabildo, el 26 de agosto de $1479{ }^{77}$. En 1495 los Reyes Católicos conceden para la ampliación del convento de Santa Clara «unas casas contiguas que havían sido de los judíos expulsos y sus sinagogas» ${ }^{78}$.

En la Plaza habitan Mosé Çarfaty ${ }^{79}$, quizá es la vivienda que tiene en censo su mujer en $1485^{80}$, Isaque Molho e Isaque Cohén, y los herederos de rabí Abrahán, que arriendan una casa en la entrada de la calle del Sol, la cual luego disfruta Mayr Cohén ${ }^{81}$.

En la Calle Rúa viven doña Ester, mujer de Salamón Abenhabibe, y sus hijos, que venden la propiedad a Yuçé Caçes hijo de Mosé Caçes, vecinos de Abrahán Pachorra y de don Mayr Cohén (1479) ${ }^{82}$. Yuçé Castaño compra una vivienda en esta misma calle (1479) ${ }^{83}$ y tiene una casa bodega y la vivienda que perteneció a su suegro rabí Simuel, la cual vende en julio de $1492^{84}$. Isabel Rodríguez Yanguas, viuda de Rodrigo de Carvajal, vende a don Mayr Cohén una casa en la Rúa (1487) ${ }^{85}$. Entre los años de 1481 y 1492 viven en la Rúa Simuel, hijo de Beroha, cuya casa está a la entrada de la calle; Harari (o Harati), los herederos de doña Reina, mujer de Çid Bueno, Yuçé Caçes, hijo de Yudá Caçes, Hayn Castaño, Yuçé Escapa, los herederos de Yudá Caçes que tienen una calleja a espaldas de

\footnotetext{
${ }^{76}$ ACP, leg. 14, núm. 42, fol. 4v; citado por SÁNCHEZ LORO Parecer págs. 679-680.

${ }^{77}$ ACP, leg. 86, núm. 9.

78 Morales Privilegios fols. 360-360v; y Benavides CheCA Prelados págs. 169-170.

${ }^{79}$ ACP, leg. 86, núm. 9, fol. 52.

${ }^{80}$ AHPC, Legado Paredes, leg. 13, núm. 15: «Escritura de zenso a favor del hospital de doña Engracia de Monroy y de $1.000 \mathrm{mrs}$. de renta en cada un año contra don Juan de Vargas y Tamamyo veçino desta ziudad».

${ }^{81}$ ACP, ACC, Libro núm. 3, fol. 84; recogido por PAREDEs GUILLÉN Zúñigas pág. 128, y López MARTín Paisaje urbano pág. 223.

82 ACP, leg. 5, núm. 33.

83 ACP, leg. 5, núm. 31.

${ }^{84}$ ACP, leg. 6, núm. 30bis, fols. 7-8v.

85 ACP, leg. 2, núm. 56.
} 
la casa de Yudá cuyo censo traspasan a Hayn Moxudo ${ }^{86}$. También viven en la calle Rúa hasta el decreto de expulsión Isaque Cohén y Hazibuena, hija de Salamón Abenhabibe y de doña Ester, cuyo edificio linda con la calle Trujillo, la casa de Yudá Moxudo y la de Mayr Cohén, yerno de Molho ${ }^{87}$. Otros inquilinos son Yuçé Caçes, el viejo, y doña Luna, vecinos de Abenhabibe ${ }^{88}$, e Isaque Molho, vecino de Isaque Abenhabibe ${ }^{89}$.

Yuçé de Medellín tiene arrendadas tres casas en la calle San Martín, una de ellas esquina a la Plaza, y los herederos de Mayr Cohén una vivienda en esta misma arteria urbana ${ }^{90}$. Los herederos de Mayr Cohén dividen una casa en dos viviendas, muy posiblemente para dar cobijo a unidades familiares independientes de reciente formación.

Así pues, la nueva judería y sinagoga se construyen en los solares que tienen los Carvajal en la calle Trujillo, cuyo barrio se consolida en 1485, pero los judíos continúan viviendo también en la calle Rúa y la Plaza hasta el decreto de expulsión, con lo cual el apartamiento hebreo de 1480 no tiene carácter restrictivo.

Judíos y cristianos comparten algunas de las calles principales de la ciudad. Suelen ser gente del estado eclesiástico (arcediano, deán, chantre, canónigo), funcionarios de la administración pública (notarios) y miembros de la nobleza (Carvajal y Núñez). En cambio no es frecuente que judíos y musulmanes residan en el mismo barrio salvo en dos casos excepcionales. Mahomat Famat arrienda al cabildo la casa de la panadería de la Plaza que tiene en alquiler Abrahán Chicala en $1434{ }^{91}$ y Simuel Aruso y el musulmán Adorraheme son vecinos también en la Plaza en $1438{ }^{92}$. Los judíos suelen estar agrupados por familias en una misma calle. En la Rúa comparten vecindad los Abenhabibe y los Cohén por un lado, y los Molho, Aruso y

86 ACP, ACC, Libro núm. 3, fols. 81-82v; y BenAvides CHECA Prelados págs. 81-82, y López MARTín Paisaje urbano pág. 122.

87 ACP, leg. 8, núm. 17.

${ }_{88}$ ACP, leg. 5, núm. 27, y leg. 8, núm. 19.

${ }^{89}$ ACP, leg. 5, núm. 29, y leg. 8, núm. 18.

${ }^{90} \mathrm{ACP}, \mathrm{ACC}$, Libro núm. 3, fol. 83; recogido por López MARTín Paisaje urbano pág. 189.

91 ACP, ACC, Libro núm. 1, fol. 80.

92 ACP, ACC, Libro núm. 1, fol. 142. 
Cohén por otro, todos ellos unidos por vínculos sanguíneos. En la calle Trujillo residen los hermanos Alegre y Lozano; y en la Plaza los Moxudo.

Otras propiedades que los judíos tienen arrendadas al cabildo en el término de la ciudad de Plasencia son las fincas rústicas, principalmente viñedos. En el término de «Pajarejos», camino de Trujillo, está «la heredad que dicen de Samuel» (1379) ${ }^{93}$. Don Menahén alquila la viña de «Los Caballos» (1411) ${ }^{94}$, que arrienda Yuçé Castaño en el último tercio del siglo XV ${ }^{95}$. Un tal Caçes arrienda un viñedo al cabildo (1471) y el herrero Simuel Aranón otras dos viñas (1481) ${ }^{96}$. Al filo de los 90 del siglo XV Isay tiene en renta un parral camino de Malpartida y un terreno en los Barriales ${ }^{97}$. Los herederos de Yuçaf, especiero, venden un parral en el vado de San Juan (década de los 80) ${ }^{98}$ e Isaque Molho adquiere al cabildo catedralicio la viña «El Cerezo" ${ }^{99}$.

También los judíos son propietarios de otros terrenos agrícolas, algunos de los cuales venden al deán Diego de Jerez por mediación de don Yuçé Castaño, apoderado de la aljama de Plasencia, en julio de 1492, entre cuyos bienes desglosamos ${ }^{100}$ : una viña vieja, un majuelo y dos viñedos en el término de Calzones, un parral en el río Jerte en el camino del Valle, dos viñas en Valdemorillos, una de ellas con olivas, membrillos y otros árboles, una viña en los Barriales y una huerta. Desconocemos los datos sobre la extensión de las propiedades agrícolas y el nivel de productividad.

Las actividades laborales de los judíos de Plasencia abarcan un amplio espectro socioeconómico: artesanos, comerciantes, tenderos, arrendadores de rentas y posiblemente el sector social de los menesterosos, que no registran las escrituras, sin descuidar las funciones relacionadas con las necesidades del

\footnotetext{
93 ACP, leg. 13, núm. 19.

94 Véase Apéndice infra, doc. 1.

95 ACP, ACC, Libro núm. 3, fols. 147 y 164.

96 ACP, ACC, Libro núm. 3, fols. 147 y 173.

97 ACP, ACC, Libro núm. 3, fols. 91v y 145v.

98 ACP, ACC, Libro núm. 3, fols. 93, 146v y 195.

99 ACP, ACC, Libro núm. 3, fols. 94 y $147 \mathrm{v}$.

100 ACP, leg. 6, núm. 30bis, fols. 7-7v.
} 
culto ${ }^{101}$. En las labores de la zapatería hallamos a las familias Aruso, Castaño, Castro, Cohén y Molho. Mosé Aranón y un tal Sentó tienen su propia herrería. En el oficio de la sastrería trabajan los Cohén y Saboca ${ }^{102}$. Zapateros, herreros y sastres tienen sus talleres en la planta baja de la calle Rúa. Los Caçes y Cohén figuran como traperos y tundidores. Hay un carnicero llamado Simuel Abençur, un Yuçaf especiero y un «maestro Moyses». En la familia Abenhabibe hay un platero y un jubetero. Otro jubetero encontramos en la familia Daça. Y un tal rabí Yudá desempeña el oficio de tamboretero.

La comunidad hebrea tiene sus propios cirujanos. Menahén en 1411 y Salamón en la década de los 60-70 del siglo XV. Un tal rabí Salamón, médico de profesión - no es rabí Salamón cirujano-, presta sus servicios al municipio con un sueldo fijo que le rebaja el concejo en enero de $1464{ }^{103}$. Posiblemente también hay un boticario judío contratado por el municipio, porque el 3 de marzo de 1492 la corona prohibe a los judíos de Plasencia desempeñar los oficios de boticario, especiero y cirujano, y tampoco les permiten tener abierta al público tiendas de pescado, aceite y alimentos ${ }^{104}$.

Muchos de esos judíos alternan sus actividades profesionales con el arrendamiento de las rentas de las alcabalas y tercias del señorío de Plasencia entre los años de 1442 y $1488^{105}$, cuyo peculio supone un complemento adicional a la economía familiar. En opinión de J. M. López Martín ${ }^{106}$ el 12\% de los placentinos que desarrollan sus actividades artesanales, comerciales y liberales en la Plaza Mayor pertenecen al credo mosaico.

De la organización comunal de la aljama de Plasencia sabemos que la comunidad tiene sus propios jueces o dayanes para

\footnotetext{
101 Datos extraídos del ACP, ACC, Libros núms. 1 y 3; los legajos citados del ACP; y AHN, Nobleza, Osuna, leg. 300, núm. 9/1.

102 Encontramos ese patronímico en un texto de dudosa transcripción efectuado en el siglo XViIr; cfr. AHN, Sección Nobleza, Osuna, leg. 300, núm. 9/1, sin foliar.

103 «Otrosy quitaron a rabi Salamon quinientos mrs. quedale dos mill de salario» (AMP«Actas Municipales [1461-1465]» fol. 25).

104 AGS, RGS (3 marzo 1492) fol. 185.

105 AHN, Sección Nobleza, Osuna, leg. 300, núm. 9/1; de donde lo toman LADERO QUESADA «Rentas condales» págs. 235-265, y El siglo XV en Castilla: Fuentes de renta y política fiscal (Barcelona 1982) págs. 168-189; y CAROLINA DE SANTOS El siglo XV págs. 194-204.

106 Paisaje urbano págs. 223 y 434-435.
} 
juzgar las demandas presentadas, aunque las escrituras no especifican si se trata en las causas civiles o criminales. No deben faltar los cargos de tesorero e inspector público de la aljama. En la escribanía hallamos a rabí Abrahán en 1492. Es posible que hubiese un rabino dedicado a la enseñanza de la Torá que impartiría sus enseñanzas en alguna de las tres dependencias anexas a la sinagoga. En el cargo de veedores de la aljama encontramos en 1492 a don Yuçé Caçes, su hijo rabí Mosé Caçes, don Ysay Pachén y Abrahán Aruso.

\section{Las familias abenataf y Abenhabibe}

Del manojo de textos encontrados en el Archivo catedralicio hemos seleccionado varios documentos de interés que nos permiten conocer aspectos específicos de las familias judías placentinas Abenataf y Abenhabibe.

El primer texto seleccionado es una carta de compraventa fechada el 4 de noviembre de $1461{ }^{107}$ que contiene una escritura redactada en castellano y otra en hebreo. El documento castellano consta a su vez de dos cartas. En la primera de ellas el titular de la hacienda, doña Vellida, esposa de Yebdá Abenataf, en su nombre, en el de sus hijos Abrahán, Yentó y Yuçef Abenataf y en el de su yerno Çid Bueno, vende a otro de sus yernos, Salamón Abenhabibe, de profesión jubetero, su casa de la calle Rúa. Doña Vellida tiene por vecinos a Mosé Abollamín, que habita en una vivienda propiedad de don Hayn Moxudo, y a Martín González, de Cuacos.

En una de las cláusulas contractuales, Yuçef Abenataf y su cuñado Çid Bueno venden a Salamón Abenhabibe las dos cuartas partes de la casa, y doña Vellida y sus otros dos hijos «todas las otras partes que yo e ellos avemos en las dichas casas», cuya venta fijan en 20.000 maravedís, que reciben en doblas y florines de oro del reino de Aragón.

Seguidamente la escritura notarial desarrolla una serie de requisitos legales y promesas formuladas por ambas partes, como la renuncia a sus derechos legítimos y a los privilegios de la corona, nobleza e Iglesia, apartarse de las jurisdicciones civil y eclesiástica, etc. Diego López, escribano de Plasencia,

107 Véase Apéndice infra, doc. 5; y J. L. LACAVE, «Documentos hebreos de Plasencia», Sefarad 59 (1999) en prensa. 
redacta el documento en presencia de los testigos Benito Sánchez, de Atienza, Alfonso Ferrándes, de Toril (lugar del Campo Arañuelo), y Mosé Abollamín, Abrahán Abençur y Salamón Molho, hijo de Çid Bueno. De los más de 35 contratos a los que hemos tenido acceso en el curso de nuestra investigación, realizados todos ellos en escribanías cristianas entre los años de 1434 a 1492, sólo en tres ocasiones figuran testigos judíos. Isaque Molho, rabí Salamón cirujano y rabí Salamón médico testifican en una escritura de venta efectuada en mayo de $1474{ }^{108}$, don Isaque Molho participa en la realizada en junio de $1485^{109}$, y por último, los testigos citados en el presente documento.

La segunda escritura, incluida en el primer texto documental, muestra a Salamón Abenhabibe tomando posesión de la hacienda en presencia de su suegra y cuñados. El propietario desarrolla el ritual de abrir la puerta de la casa, caminar por las habitaciones, encerrarse dentro de ellas y abrir y cerrar de nuevo la puerta desde la calle. Acabado el protocolo, Salamón Abenhabibe «dexo de su mano a la dicha doña Vellida para que biniese e morase en ellas mientras su voluntad fuere», cuya escritura se realiza el mismo día en la misma escribanía y con los mismos testigos.

La década de los 60 es una época de inestabilidad política en la que el Ayuntamiento de Plasencia alterna ciclos de tolerancia con medidas marginales contra los judíos. En mayo de 1464 el concejo permite que el empadronador y «cogedor» judío de la moneda forera, rabí Abrahán Aboaf ${ }^{110}$, preste juramento "segund su ley» ${ }^{111}$ en el cumplimiento de sus atribuciones fiscales. En setiembre de 1476 Isay Abenhabibe arrienda al cabildo una viña situada en el puente de Nieblas, cerca de la «Dehesa de los Caballos», cuyo contrato notarial refiere que «juro el dicho don Ysay en la su ley de haser bien pago» ${ }^{112}$.

El texto del juramento judío emitido por rabí Abrahán Aboaf e Isay Abenhabibe posiblemente es muy similar al recogido en el

\footnotetext{
108 Véase Apéndice infra, doc. 7.

109 Véase Apéndice infra, doc. 9.

110 AHN, Sección Nobleza, Osuna, leg. 300, núm. 9/1.

111 AMP, «Actas Municipales (1461-1465)» fol. 31.

112 Véase Apéndice infra, doc. 8.
} 
doc. 9 (Apéndice infra), formado a su vez por tres escrituras del mismo tenor fechadas el 26 de junio de 1485 ante el mismo escribano y testigos. En la primera carta doña Vellida, viuda de Salamón Molho, vende a su yerno Yuçé Aruso el mozo las casas que tiene «en la juderia de la calle de Trugillo», que limitan con la de su yerno Abrahán Cohén y la de Yuçé de Medellín por $8.000 \mathrm{mrs}$., un censo de $200 \mathrm{mrs}$. y tres pares de gallinas anuales. Efectúan el traspaso de la propiedad en la escribanía de Diego López, con la participación de los testigos Pedro de Trujillo, Alonso de Piñares e Isaque Molho.

En el segundo cuerpo de la escritura, doña Vellida extiende una carta de juramento según la ley de los judíos en virtud de la cual se compromete a respetar las condiciones del contrato ${ }^{113}$ firmado con el signo del escribano Diego López, los dos testigos cristianos e Isaque Molho.

El tercer texto documental es una «carta de mercedes» en la cual Yuçé, Habine y Oro, con licencia y autoridad de su madre doña Vellida, aceptan las condiciones del contrato de venta y renuncian a la posesión de las casas vendidas. Los tres hermanos formulan el juramento judío recogido por el escribano cristiano en presencia de los citados testigos.

En la documentación notarial que hemos encontrado en los archivos hallamos a otros miembros de la familia Abenhabibe y Abenataf. Del matrimonio Yebdá Abenataf y doña Vellida nacen cinco hijos: Yentó, Abrahán, Yuçef, una hija cuyo nombre desconocemos, quizá llamada Reina, casada con Çid Bueno, y Ester, mujer de Salamón Abenhabibe, de cuyo matrimonio nacen Hazibuena, que contrae nupcias con Isaque Cohén, e Isaque Abenhabibe, casado con Reina.

Isaque Abenhabibe es hijo de Salamón Abenhabibe y de doña Ester y su hermana Hazibuena es la esposa de Isaque Cohén. Posiblemente este Isaque Cohén es el que vive en la calle Rúa al lado de su cuñado Isaque Abenhabibe ${ }^{114}$. Otros miembros de la familia Abenhabibe residentes en Plasencia

\footnotetext{
${ }^{113}$ El juramento judío es un texto extractado similar al formulado por los judíos de Castilla y León, publicado en Cortes de los antiguos Reinos de León y Castilla (Madrid 1861) págs. 82-84; y J. AMAdOR DE Los Ríos, Historia de los judios de España y Portugal (Madrid 1984) vol. I págs. 567-569.

114 ACP, legs. 5, núm. 29; 8, núm. 8; y 6, núm. 30bis.
} 
son Menahén Abenhabibe ${ }^{115}$ y rabí Yuçé Abenhabibe que tienen cargos de responsabilidad en la aljama en $1492{ }^{116}$.

Otros miembros de la familia Abenataf cuyo grado de parentesco ignoramos son Simón Abenataf, vecino de la comunidad hebrea de Aldeanueva del Camino ${ }^{117}$, tierra de Plasencia, que puja en la renta de las alcabalas del poblado en 1466 y 1479. Abrahán Abenataf, de la aljama de Cabezuela del Valle, que interviene en la subasta de las alcabalas de Ojalvo (comarca del Jerte) en 1479. Y por último, Yudá Abenataf, residente en Plasencia, al que encontramos pujando en la subasta de la alcabala de la almoneda y ropa vieja de Plasencia en $1488{ }^{118}$.

En el capítulo de propiedades de explotación agrícola; Yuçé Abenhabibe disfruta de un parral en el vado de San Juan (1450) ${ }^{119}$, don Ysay Abenhabibe arrienda una viña en el puente de Nieblas y tiene otra finca en el camino de Gargüera (1476) ${ }^{120}$, y Salamón Abenhabibe tiene arrendado al cabildo un viñedo y un parral en el vado de San Juan que alquila su yerno Isaque Cohén en los años $80^{121}$.

Un breve esquema del árbol genealógico de los Abenataf y Abenhabibe sería ${ }^{122:}$

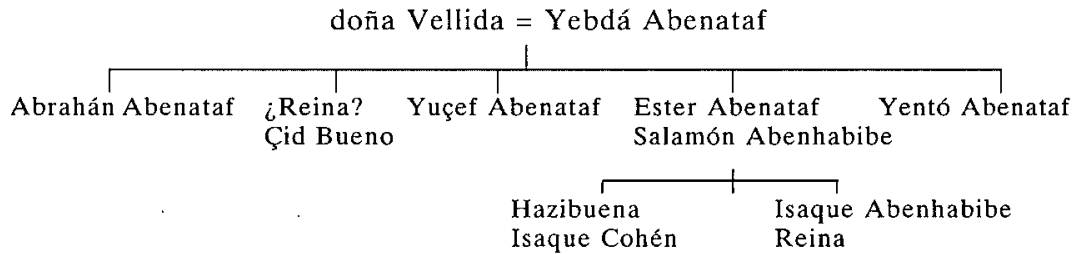

115 AHN, Sección Nobleza, Osuna, leg. 300, núm. 9/1.

116 ACP, leg. 6, núm. 30, fol. 5.

117 En la renta de 1464: «Xrino Abenataf vezino de Segura», y en la de 1479: «Ximon Abenatas vezino de Aldeanueua» (AHN, Sección Nobleza, Osuna, leg. 300 núm. 9/1).

118 AHN, Sección Nobleza, Osuna, leg. 300, núm. 9/1.

119 ACP, ACC, Libro núm. 3, fol. 197v.

120 Véase Apéndice infra, doc. 8.

121 ACP, ACC, Libro núm. 3, fols. 93, 146v y 195.

122 AHN, Sección Nobleza, Osuna, leg. 300, núm. 9/1; véase Apéndice infra, docs. 5 y 8 ; y ACP, leg. 8 , núm. 17. 


\section{LA DESINTEGRACIÓN DE LA ALJAMA (1492)}

Cuando la ciudad de Plasencia retorna a la corona en octubre de $1488^{123}$, los Reyes Católicos ratifican a petición de la comunidad hebrea el emplazamiento de la judería de la calle Trujillo ${ }^{124}$. Apenas dos años después los miembros de la corporación municipal destapan en la ciudad el tarro de las esencias antijudías, preservado hasta la fecha por el gobierno del dignatario Álvaro de Zúñiga ${ }^{125}$. En 1489 asumen el control del municipio los caballeros Gutierre de Carvajal, Garci López de Carvajal, el comendador Fernando de Trejo, Pedro Suárez Villalobos, Pedro de Ahumada, Álvaro de Quirós, Nuño Pamo y Pedro de Ahumada, entre los cuales se encuentran enemigos y aliados de los judíos ${ }^{126}$. La promiscuidad de judíos y cristianos en las calles Rúa y Trujillo es el subterfugio político usado por el Ayuntamiento y los principales caballeros de la ciudad para dar rienda suelta a su antijudaísmo en los meses de marzo y junio de $1491{ }^{127}$. Es sintomático que a partir de 1488 apenas encontremos en la documentación civil y eclesiástica contratos de venta y alquileres de casas por los cristianos a los judíos.

Así llegamos a los días del decreto de expulsión de 1492. En esas fechas la comunidad hebrea de Plasencia tiene arrendada al cabildo catedralicio 19 casas distribuidas en las calles Trujillo (4), Rúa (8), San Martín (4), Sol (1) y Plaza (1).

Pero también tienen los judíos otros bienes privados y comunitarios en propiedad, que los desterrados transmiten al mejor postor en un breve espacio de tiempo. En la asamblea general celebrada en la aljama el 21 de mayo de 1492, don Yucé Caçes, su hijo rabí Mosé Caçes, don Ysay Pachén y Abrahán Aruso en calidad de veedores, el escribano rabí Abrahán, Çid Bueno y Yuçé Aruso apoderan a Yuçé Castaño «para que en nonbre de la dicha aljama podades vender todos e qualesquier bienes

\footnotetext{
123 AHN, Sección Nobleza, Osuna, leg. 300, núm. 8.

124 AGS, RGS (11 mayo 1491) fol. 86.

${ }^{125}$ En los días de los Zúñiga también hubo momentos de crisis en las relaciones entre judíos y cristianos, véase AMP, «Actas Municipales (1461-1465)», fols. $28 \mathrm{v}, 30 \mathrm{v}$ y $43 \mathrm{v}$.

${ }^{126}$ BPC, Legado Paredes, Ms. 3, « $3^{\circ}$ Apuntamiento con indice», fols. 229 y $374 \mathrm{v}$.

127 SuÁrez Fernández Documentos docs. 149, 155 y 158.
} 
e cosas pertenesçiente a la dicha aljama» ${ }^{128}$. Sorprende en la escritura de apoderamiento la participación de testigos cristianos miembros de la servidumbre del deán de Plasencia, Diego de Jerez. Así, Diego de Medina es su administrador de 1491 a $1501{ }^{129}$, su criado Alonso de Torralba es algún tiempo después notario por la autoridad apostólica y ordinaria y de número de la ciudad y obispado de Plasencia ${ }^{130}$, y Alonso de Soria.

Ese mismo día Yuçé Caçes formaliza con el deán de Plasencia la escritura de venta y donación de «los honsarios de los judios de la dicha aljama asy viejos como nuevos que tenemos y la dicha aljama tiene en el Berrocal desta çibdad, con toda la piedra e canteria que en ellos esta e en cada vno dellos labrada y por labrar, asy sobre las sepolturas e enterramientos que esta en los dichos honsarios» 131 por la cifra de 400 reales de plata. En esta ocasión actúan como testigos el comendador Juan Osorio, de Montemayor del Río, el escribano Diego López y los criados del deán Francisco de Toro (de 1486 a 1496) ${ }^{132}$, Alonso de Torralba y Lorenzo Benavides (1492?$1507)^{133}$. El notario Fernando Díaz de Soria formaliza la escritura.

El mismo día 21 de mayo don Yuçé Castaño hace lectura pública del contrato de venta y donación ante los cuatro veedores de la aljama, además de don Mayr Cohén, maestre Moisés, Gabriel Moxudo, el escribano rabí Abrahán, Yuçé y Sentó Haravón, Abrahán Caçes, rabí Yuçé Abenhabibe y otros muchos judíos de la aljama, resaltando que el valor real de los osarios y materiales de piedra «son en mayor suma e cantidad que no es el valor de la tal demasya de los dichos quatroçientos reales [de plata] lo qual nos asy conosçemos», cuya propiedad incluye «toda la piedra dellos e canteria labrada e por labrar e con su tierra e sitios deslindados» ${ }^{134}$. Participan

\footnotetext{
128 Véase Apéndice infra, doc. 11/1.

129 ACP, leg. 2, núm. 34, fols. 23v-25; recogido por SÁNCHEZ LoRO Parecer pág. 910.

${ }_{130} \mathrm{ACP}$, leg. 2, núm. 34, fols. 40v-41v; recogido por SÁnCHEZ LoRO Parecer págs. 940 y 976.

131 Véase Apéndice infra, doc. 11/2.

132 ACP, legs. 2, núm. 34, fol. 24; y 13, núm. 44; recogido por SÁNCHEZ LORO Parecer pág. 909.

133 ACP, leg. 2, núm. 34, fols. 16v-17; y SÁNCHEZ LORO Parecer pág. 898.

134 Véase Apéndice infra, doc. 11/3.
} 
como testigos Fernando de Carvajal, su criado Ahumada, el clérigo Alonso Fernández y el sastre Fernando de Peñaranda. Es muy posible que el deán hubiese convenido con la aljama hebrea en una fecha anterior la venta de los osarios, que formalizan oficialmente ante escribano en las mencionadas escrituras. En cualquier caso la venta de los osarios es el pistoletazo de salida que da pie a la compra por el deán de propiedades a los judíos que deciden abandonar la ciudad de Plasencia y Jaraíz de la Vera.

En 1496 el deán Diego de Jerez vende el cementerio a la ciudad, «a la cual -dice fr. A. Fernández- valen sus réditos de pasto y labor buena suma de dineros» ${ }^{135}$. En 1510 el cementerio hebreo forma parte de los baldíos del Ayuntamiento ${ }^{136}$. Una nueva descripción del estado en que se encuentra el osario hebreo la encontramos en la pluma de A. Matías Gil en $1877^{137}$ :

hoy mismo pueden verse unos veinte y tantos [sepulcros] abiertos y agrupados ... presentando la forma del cuerpo humano envuelto en el sudario hebreo; son una caja abierta desde los pies á los hombros en la forma de ataud, y otra caja abierta en la misma piedra y unida á la anterior recibia la cabeza del cadaver, que luego se cerraba con una losa que cubria este deposito para lo que tenia sus rebajes en todo el borde.

En cuanto al edificio de la sinagoga pasa a manos de los Reyes Católicos, controlada por el corregidor de la ciudad. Sin embargo, en los planes de la Comunidad de curas y beneficiados de Plasencia está el deseo de transformarla en iglesia en honor de la reina Isabel y acomodarla para celebrar sus reuniones eclesiásticas. Por esta razón, el abad de la universidad de clérigos persuade a Rodrigo de Ávila, prelado de la iglesia catedral de Plasencia, para que solicite a la corona la cesión del inmueble, cuya petición formaliza el 6 de noviembre de $1492{ }^{138}$. El 11 de

\footnotetext{
135 FERnández Anales fol. 155.

136 «En la heredad que dicen el Berrocal de Garci Lopez, que ha por linderos de la una partte valdios destta dicha cibdad e de la otra el rio Xerette e de la ottra la heredad que dicen Palacios, ques de Garci Lopez de Carvajal» (ACP, leg. 5, núm. 23, capellanía Diego Gómez de Jerez, 18 dic. 1510).

137 Matías Gil Centurias pág. 136; recogido literalmente por Díaz y PÉRez Extremadura pág. 918, y PAREDES GUILLÉN Zúñigas pág. 129. En la actualidad hay una docena de tumbas antropomórficas en mal estado de conservación.

${ }^{138}$ Extraemos la información de varias hojas manuscritas sueltas que hemos encontrado en ACP, leg. 86, núm. 9, fol. 139.
} 
enero de 1493 los Reyes Católicos hacen merced al cabildo de curas de la sinagoga con las tres dependencias anexas ${ }^{139}$, cuya llave entrega el corregidor de la ciudad Ferrando Díaz del Castillo al clérigo Pedro López, abad del cabildo de la universidad de clérigos, el 2 de febrero de $1493^{140}$.

El edificio de la sinagoga se mantiene en pie hasta que estalla la guerra de los Comuneros de Castilla. Parece ser que en la primavera de 1520 el estado nobiliario y una parte del cabildo eclesiástico toman las riendas de la rebelión comunera, fragmentando la ciudad en dos bandos fratricidas liderados por las familias Carvajal y Zúñiga, enconados rivales y enemigos ${ }^{141}$. En el telón de fondo de la contienda se proyecta la ambición de una nobleza feudataria que desea preservar e incrementar a cualquier precio su parcela de poder en la sociedad, al margen de las reivindicaciones sociales del pueblo llano ${ }^{142}$. En las Actas del Cabildo Catedralicio de 20 de abril de 1520 leemos que «estan tomadas las yglesias e torres e encanelladas con gente armada, y desta manera todas las casas de cavalleros e la cibdad esta encastillada e se vela e guarda» ${ }^{143}$.

Otra fuente informa que entre el 26 de agosto y primeros de septiembre los Carvajal «tyenen las mas yglesias encastylladas, e estan quemadas en esta cibdad por los de una parte e por lo de otra mas de sesenta o setenta pares de casas» ${ }^{144}$. El 28 de agosto el cabildo catedralicio nombra dos diputados de su estado para representar a la Comunidad que recaen en el deán Gómez de Jerez y en Bernardino de Carvajal, arcediano de Plasencia ${ }^{145}$, a los que sus compañeros de cabildo les acusan

139 AGS, RGS (11 en. 1493) fol. 18; y ACP, leg. 282, núm. 11.

140 ACP, leg. 282, núm. 11, fol. 1v.

141 Cfr. "Historia crítica y documentada de las Comunidades de Castilla», Memorial Histórico Español 35 (Madrid 1897) págs. 538-540; 36 (Madrid 1898) págs. $133-145,435-438$ y $598 ; 37$ (1898) págs. 527 y 686-687; y 38 (1898) págs. $250,319,506$ y 609 .

142 Para E. COOPER, Castillos señoriales en la Corona de Castilla (Salamanca 1991) vol. I, 1 pág. 138: «en Plasencia, la Comunidad fue una reacción popular ante el temor de que Carlos V restituyera el señorío de los Zúñiga y con ello el predominio en la ciudad de los intereses de la Mesta».

143 ACP, «Traslado autentico de este libro de Actas de Cabildos de 1514 a $1535 »$, fols. 143-144v.

144 «Historia crítica», Memorial Histórico Español 36 pág. 137; posiblemente el autor de esta noticia se basa en las fuentes del cabildo catedralicio.

145 ACP, «Traslado autentico ... de 1514 a 1535», fols. 152-153v; Gómez de Jerez es hijo del deán Diego de Jerez. 
de ser los promotores de la revuelta: «e como a cabsa de los dichos señores dean e arcediano de Plasencia estava esta cibdad tan rebuelta e en tantas diferencias e discordias» ${ }^{146}$.

La sinagoga de la calle Trujillo, ubicada en el feudo de los Carvajal, es uno de los edificios incendiados en las discordias mantenidas entre los Carvajal y los Zúñiga entre los meses de abril y agosto de 1520 , no quedando «della mas de unos pedaços de paredes y aun aquellos quedaron muy quemados ... y dende entonçes aca [1520-1540] esta hecha corrales y los vezinos çercanos tienen sacados vnos portillos y por ellos echan vasura» ${ }^{147}$.

En enero de 1524 el cabildo catedralicio entorpece las diligencias del juez pesquisidor que investiga «sobre los daños y quemas de las casas que en ella se quemaron al tiempo de las alteraciones y movimientos que en esta cibdad ovo [y] procede contra algunos de los señores beneficiados del dicho cabildo». El cabildo catedralicio respalda al provisor Bernardino de Carvajal en sus acciones judiciales y propone financiar con los bienes de la mesa capitular los gastos del juicio e indemnizar al reo que fuese desterrado reservándole su oficio y residencia en la iglesia ${ }^{148}$.

[Continuará]

146 ACP, «Traslado autentico ... de 1514 a $1535 »$, fols. 173-173v.

147 ACP, leg. 269, núm. 17 (declaraciones de Diego Hernández Floriano). ¿Este Diego es hermano del capitán Francisco Hernández Floriano, que acompaña a los judíos en su exilio a Portugal?; cfr. Fernández Anales fol. 155.

148 ACP, "Traslado autentico ... de 1514 a 1535 ", fols. 231 v-233. Los cuatro inculpados en la destrucción de la sinagoga pagaron $85.000 \mathrm{mrs}$; cfr. ACP, leg. 269, núm 17, fol. 9; y AGS, RGS (25 ag. 1526) sin foliar, recogido por COOPER Castillos pág. 138. En el solar se levantó a mediados del siglo Xvi la casa de los Carvajal-Girón. 